\title{
Progradation of the Yellow (Huanghe) River delta in response to the implementation of a basin-scale water regulation program
}

\author{
Yuanyuan Zhou ${ }^{a}$, He Qing Huang a,*, Gerald C. Nanson ${ }^{b}$, Chong Huang ${ }^{c}$, Gaohuan Liu ${ }^{c}$ \\ a Key Laboratory of Water Cycle and Related Land Surface Processes, Institute of Geographic Sciences and Natural Resources Research, Chinese Academy of Sciences, Beijing 100101, China \\ b School of Earth and Environmental Sciences, University of Wollongong, NSW 2522, Australia

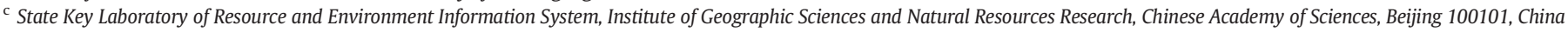

\section{A R T I C L E I N F O}

Article history:

Received 23 December 2014

Received in revised form 19 April 2015

Accepted 20 April 2015

Available online 1 May 2015

\section{Keywords:}

Yellow River delta

Water regulation

Sediment supply

Land accretion

River mouth channel

Shoreline change

\begin{abstract}
A B S T R A C T
The water and sediment supply to the lower reach and estuary of the Yellow (Huanghe) River have been altered to a very significant degree by the construction of numerous small to large reservoirs and the progressive implementation of water and soil conservation measures across the entire drainage basin since the late 1950s, followed by a basin-scale water regulation program since 2002. There is an urgent need to know how progradation of the Yellow River delta (YRD), an area on which people live and farm, has continued and will continue to respond to these controls. This study examines the changing patterns of water and sediment supply to the YRD over the period of 1950-2013 and, using remote sensing, it evaluates the morphological changes of the delta during 1976-2013. Although both water and sediment input to the delta have been described as declining significantly since the mid 1960s, we show that since 2005 the supply of water has remained at around 20 billion $\mathrm{m}^{3} \mathrm{yr}^{-1}$ and

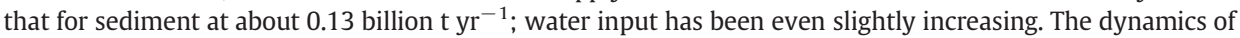
extension/shrinking and avulsion in river-mouth channels and accretion/erosion of shorelines is an integrated response to the complex variations in both sediment and water supply. This study develops a quantitative relationship between water and sediment supply and the area of land accretion and it predicts the critical condition for land accretion in the YRD. To ensure that delta land will not be lost, care is needed in the future implementation of the basin-scale water regulation program.
\end{abstract}

(c) 2015 Elsevier B.V. All rights reserved.

\section{Introduction}

The Yellow (Huanghe) River delta (YRD) is one of the most rapid sedimentation areas on Earth because the river is the most sedimentladen in the world and supplies a very large amount of sediment to its estuary each year. As it has been estimated that the Yellow River historically delivered annually some 1.08 billion t of sediment to the sea, accounting for $6 \%$ of the total fluvial terrestrial-sediment into global oceans (e.g. Milliman and Meade, 1983; Saito et al., 2007). In contrast to such dynamic river processes, the delta has been subject to relatively weak ocean dynamics due to a low tidal range and a slow rate of sealevel rise (e.g. Ren and Shi, 1986; Wang et al., 1992, 2012; Zeng, 1997; Saito et al., 2001; Hu and Cao, 2003). As a result, a large amount of sediment carried by the Yellow River has been deposited near the river mouth, forming a vast delta that has extended over $800 \mathrm{~km}$ during the Holocene from the Bohai Sea in the north to the Huanghai Sea in the south (Chinese Academy of Sciences, 1980; Hillel, 1991; Li and Finlayson, 1993; Van Gelder et al., 1994).

\footnotetext{
* Corresponding author. Tel.: +861064888992.

E-mail address: huanghq@igsnrr.ac.cn (H.Q. Huang).
}

In line with the creation of such an extensive delta, the course of the river to the sea has often changed according to historical documents over the past 4200 years (e.g. Chinese Academy of Sciences, 1980; Pang and Si, 1980; Li and Finlayson, 1993; Zeng, 1997; Saito et al., 2000). In some cases this affected a large number of people and the collapse of regional economies (e.g. Wang and Liang, 2000; Zhu et al., 2003). To reduce the oversupply of sediment and to make optimal use of the water, many approaches have been adopted, including systematically building numerous small to large reservoirs and adopting effective water and soil conserving measures across the entire basin of the Yellow River since the late 1950s. These intensive human activities, together with the regional climate change consisting of higher temperatures and the increasing frequency and intensity of droughts in recent decades, have lowered water and sediment yields significantly from the upper and middle Yellow River Basin (e.g. Fan et al., 2006a,b; Wang et al., 2007; Peng et al., 2010; Ringler et al., 2010; Yu et al., 2013a,b). Consequently, the amount of water and sediment delivered to the YRD has reduced and the rate of sedimentation in the estuary slowed greatly, causing significant coastal erosion in many parts of the delta (e.g. Chu et al., 2006; Saito et al., 2007; Wang et al., 2010; Ma et al., 2012; Yu et al., 2013a,b; Chu, 2014; Liu et al., 2014; Zhou et al., 2014). The delta today supports a human population of more than 
two million who obtain their livelihood from farming, fishing and oilexploiting, so changes to its water and sediment supply and land area can have profound impacts.

Associated with water and sediment reduction, there have been numerous times during the 1980s and 1990s when water flow to the estuary has ceased completely, causing wide ranging concern as to the health of the second largest river in China (e.g. Giodano et al., 2004; Yang et al., 2004). To address this, a water regulation program has been enforced by the government of China since 1999 and enhanced since 2002 after the Xiaolangdi Reservoir became fully operative. This regime of regulation controls the supply of water and sediment to the YRD to a significant degree and yet little is known as to how progradation and erosion of the YRD have responded.

The morphological development of a delta is determined by many factors, such as sediment input, tidal regime, wave energy, river discharge, and littoral currents (e.g. Wright and Coleman, 1973; Allison et al., 1995; Roberts, 1997; Zhao et al., 1997; McManus, 2002; Bridge, 2003; Blum and Roberts, 2009; Lamb et al., 2012; Nanson et al., 2013). Among so many potential factors, detailed studies of the changes in the accretion of the YRD during 1953-1997 have shown that sediment input is the major factor driving progradation (e.g. Wang and Liang, 2000; Chu et al., 2006; Wang et al., 2006; Bi et al., 2014), but water supply is also important (e.g. Xu, 2002; Zhang and Hu, 2007a,b; Cui and Li, 2011). Sediment input provides material for delta construction while water supply provides the dynamic conditions for sediment transport and deposition. Xu (2002) suggested that the effects of both water and sediment supply on the progradation of the YRD need to be determined in an integrated way; however, most studies so far have focused on these parameters separately (e.g. Wang et al., 2006, 2010; Cui and Li, 2011; Bi et al., 2014). The lack of an integrated approach makes it difficult to evaluate the combined effects of water and sediment supply on delta progradation.

To evaluate how the YRD tends to respond to the implementation of the basin-scale water regulation program, this study examines the changing patterns of annual runoff and sediment supply from 1950 to 2013 and assesses the degree of human control that has influenced the morphological changes of the delta. Furthermore, using remote sensing images, the extension/shrinking and avulsion of river mouth channels and the corresponding accretion/erosion patterns of the shorelines during the period 1976-2013 are analyzed. Finally, an integrated quantitative relationship between land-accretion and water and sediment supply to the YRD is developed and the potential effects of the implementation of the basin-scale water regulation program on the progradation of the YRD are evaluated.

\section{Geographic characteristics of the study area}

The vast YRD consists of two parts, the ancient delta and the modern one. They were separated in 1855 when a major switch occurred in the Yellow River's course, from the Huanghai Sea in Southeast China (south of the Shandong Peninsula) to the Bohai Sea in Northeast China (south of Tianjin) (e.g. Pang and Si, 1980; Wang and Liang, 2000; Ganti et al., 2014). Since the switch, a delta of about $6113 \mathrm{~km}^{2}$ has formed in the northeast part of Shandong Province, with the delta's vertex moving downstream gradually from Lijin (Wright et al., 1990; Li et al., 1998; Shi and Zhang, 2003) (Fig. 1).

Across the current delta, abundant wetlands have developed largely from the abandoned river mouth channels. These wetlands host a diverse biological habitat that include over 1900 ground animal and plant species, as well as over 260 bird species. Importantly, the YRD provides a resting place for migrating birds, including about 152 protected species from the inland of the northeastern Asia and the western Pacific Ocean. Because the delta has undergone rapid economic development including exploitation of its associated oil field, the question of how to keep the structure and function of these wetlands secure has been the subject of numerous studies. Negative impacts of development include seawater intrusion due to reduced water and sediment discharges and associated weakening river dynamics in recent decades (e.g. Lian et al., 2008; Ottinger et al., 2013; Kuenzer et al., 2014).

Since the modern YRD development initiated in 1855, the river's major courses to the sea have shifted frequently. The last three major courses of the river have been Shenxiangou from 1953, Diaokougou from 1964, and Qingshuigou from 1976 (Fig. 1b). The last of these is the main focus of this study because it bears a clear imprint of the influences of human intervention on the delta's development, especially the effect of the water regulation program which was implemented over the entire drainage basin of the Yellow River since 2002.

\section{Changing patterns of water and sediment supply to the YRD during 1950-2013}

\subsection{Water regulation program}

The water regulation program of the Yellow River was initiated for ensuring that the Yellow River mouth would receive water throughout the entire year. This program initially developed from a crossprovincial, quota-based water allocation agreement enforced by the Government of China in 1999 (Chen et al., 2002; Zhu et al., 2003). The main reason for implementing the program is that the YRD frequently encountered very low flows and even no-flow periods during the 1980s and the 1990s, with devastating effects on wetland ecosystems and serious water-use problems in the lower Yellow River and the YRD (Cai and Rosegrant, 2004). Three large reservoirs have been operated jointly by the Yellow River Water Conservancy Commission to control the use of water from the Yellow River in each of the eight provinces that constitute the basin (Fig. 1a), during 1999-2002. The reservoirs include the Liujiaxia and Longyangxia Reservoirs constructed on the upper Yellow River in 1974 and 1985, respectively, with respective volumes of 5.7 and 24.7 billion $\mathrm{m}^{3}$, and the Sanmenxia Reservoir built near the end of the middle Yellow River (where it leaves the uplands) in 1960 (Fig. 1a). Although the Sanmenxia Reservoir initially had a volume of 36 billion $\mathrm{m}^{3}$, heavy sedimentation after its construction has reduced its available volume to less than 1 billion $\mathrm{m}^{3}$ (Chen et al., 2002; Ma et al., 2012). Despite such a substantial loss, it still has some capacity for adjusting runoff and sediment, and the joint operation of these three large dams has successfully ended more than two decades of no-flows in the lower Yellow River and the YRD (e.g. Chen et al., 2002; Wang, 2005, 2010).

In 2002, the newest large reservoir (Xiaolangdi) became fully operational. Because of its large available volume $\left(12.65\right.$ billion $\left.\mathrm{m}^{3}\right)$ and location at the exit of the last gorge in the middle reach of the Yellow River, about $130 \mathrm{~km}$ downstream of the Sanmenxia Reservoir (Fig. 1a), it provides a very effective control over the release of water and sediment to the lower Yellow River and the YRD. This has significantly enhanced implementation of the water regulation program in the lower drainage basin. In particular, the joint operation of the four large reservoirs (Longyangxia, Liujiaxia, Sanmenxia and Xiaolangdi) not only ensures that water flow to the estuary of the Yellow River will not be cut off in dry seasons, but also makes it possible to release specially modulated water and sediment regimes through Xiaolangdi Dam to the lower reach and estuary of the Yellow River. Since 2002, this water-sediment modulated scheme has been conducted in June every year and as a result, a considerable amount of sediment deposited in the Xiaoliangdi Reservoir has been expelled out and the uplifted bed of the lower reach of the Yellow River scoured to a considerable degree (e.g. Wang et al., 2010; Chen et al., 2012; Chu, 2014). Due to the heavy deposition of sediment, the channel bed of the lower reach has become elevated above the adjacent valley floor by some 8 to $12 \mathrm{~m}$ over the past 40 years, so this water-sediment modulated scheme helps to reduce the discrepancy in channel and ground elevation (Ma et al., 2012; Chu, 2014). 


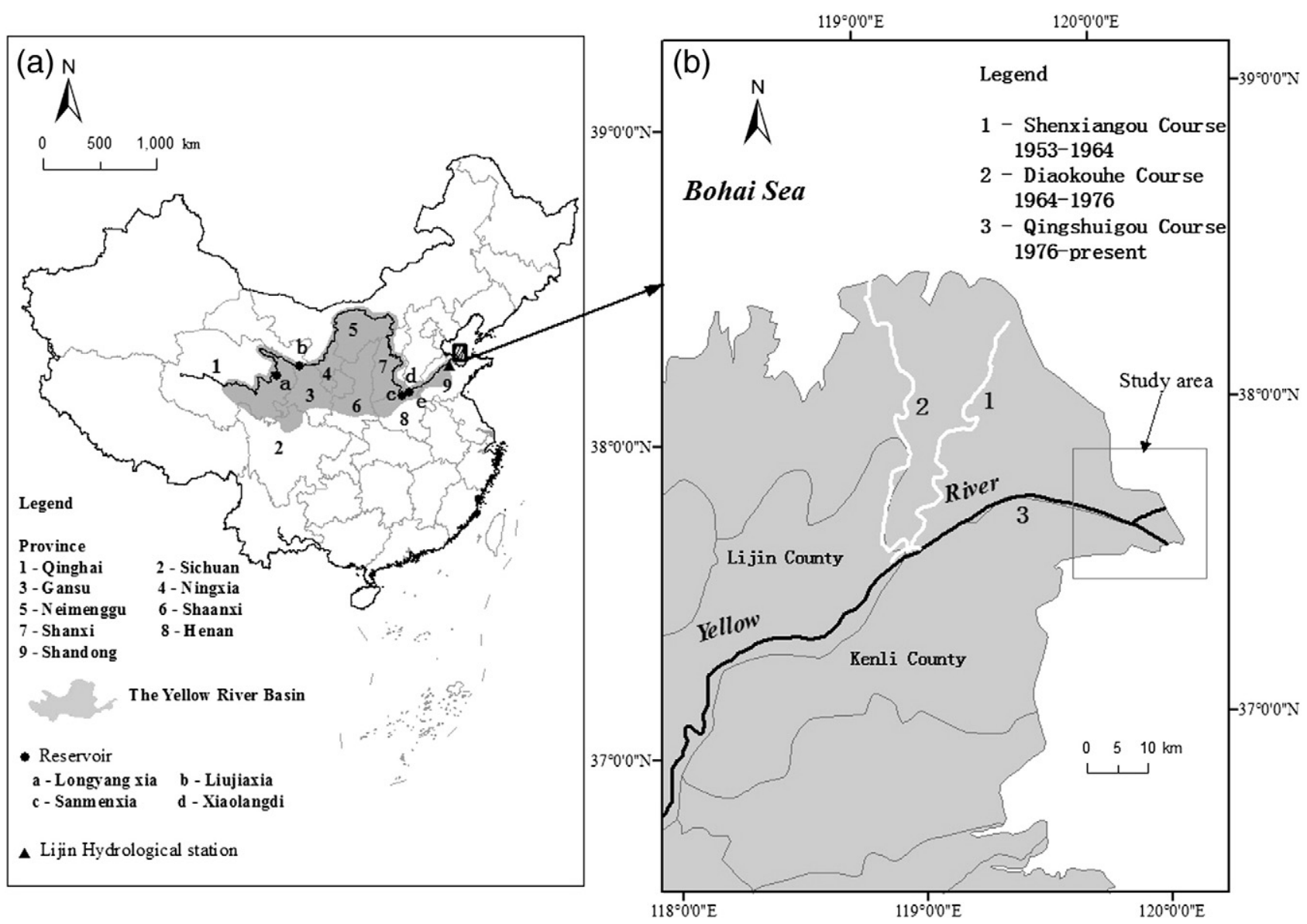

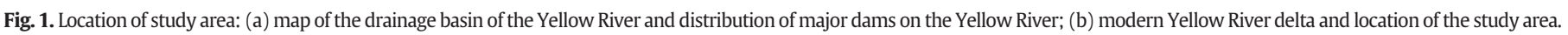

\subsection{Changing patterns of water and sediment supply to the YRD}

The Lijin hydrological gauging station, located about $100 \mathrm{~km}$ upstream from the present mouth of the Yellow River (Fig. 1a), has been recording the variations of water and sediment supply since 1950. Fig. 2 presents the temporal variations of both annual runoff and sediment load from 1950 to 2013 (the data have been made available by the Yellow River Water Conservancy Commission of China). As a whole, runoff and sediment entering the YRD have decreased respec-

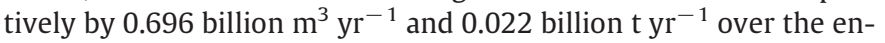
tire period. However, both annual runoff and sediment load show a significant declining trend only from about the mid 1960s. During 1996 to 2002, runoff declines to its lowest level ranging from 1.86 to 6.84 billion $\mathrm{m}^{3} \mathrm{yr}^{-1}$, while since 2003 it has increased significantly to stay at around 20 billion $\mathrm{m}^{3} \mathrm{yr}^{-1}$ over much of that time. In contrast, sediment load declines continuously since the mid 1960s until 2013.

In correspondence to the recent changes in the Yellow River course, Table 1 presents the average annual runoff and sediment supply in six periods during 1950 to 2013. The average annual runoff and sediment supply are the highest in the first period (1950-1965) when the river adopted the Shenxiangou course, $61.5 \%$ and $64.1 \%$ higher than the corresponding averages for the entire 64 years ( 30.5 billion $\mathrm{m}^{3} \mathrm{yr}^{-1}$

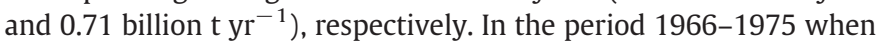
the river took the Diaokougou course, runoff declined significantly, while sediment showed a slight decrease in comparison with the period 1950-1965. Since the river adopted the Qingshuigou course in 1976, runoff had shown a stepwise declining pattern in the first three periods until 2005, while sediment has been consistently decreasing in all four periods until 2013. The lowest annual runoff occurred in the period
1996-2005 with an average value of only 10.8 billion $\mathrm{m}^{3} \mathrm{yr}^{-1}$, while the lowest sediment supply took place in the latest period 2006-2013

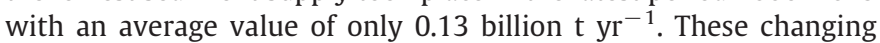
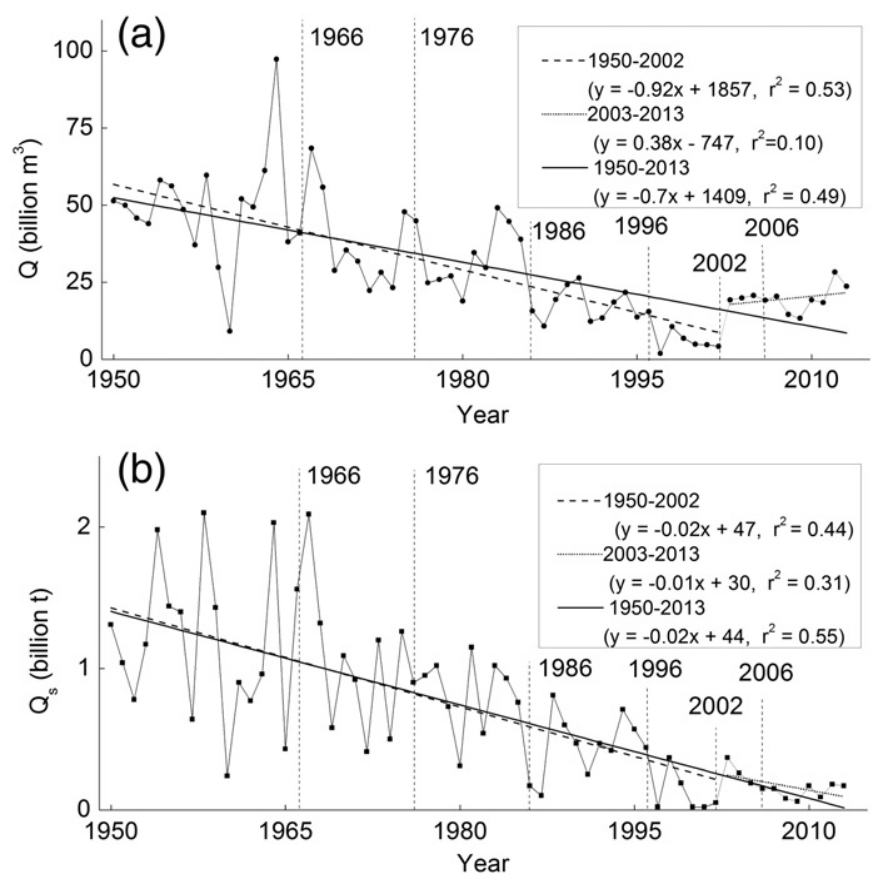

Fig. 2. Variations of annual runoff and sediment at the Lijin station during 1950-2013: (a) runoff; (b) sediment. 
Table 1

Variations of the averaged annual runoff and sediment observed at Lijin station in different periods.

\begin{tabular}{llll}
\hline No. & Period & $\begin{array}{l}\text { Average runoff } \overline{\mathrm{Q}} \\
\left(\text { billion } \mathrm{m}^{3} \mathrm{yr}^{-1} \text { ) }\right.\end{array}$ & $\begin{array}{l}\text { Average sediment } \overline{\mathrm{Q}}_{\mathrm{s}} \\
\left(\text { billion } \mathrm{yr}^{-1} \text { ) }\right.\end{array}$ \\
\hline 1 & $1950-1965$ & 49.2 & 1.16 \\
2 & $1966-1975$ & 38.3 & 1.09 \\
3 & $1976-1985$ & 33.8 & 0.83 \\
4 & $1986-1995$ & 17.6 & 0.46 \\
5 & $1996-2005$ & 10.8 & 0.19 \\
6 & $2006-2013$ & 19.6 & 0.13 \\
& $1950-2013$ & 30.5 & 0.71 \\
& $1976-2013$ & 20.5 & 0.42 \\
\hline
\end{tabular}

patterns of runoff and sediment load are closely linked to the operation of the four large reservoirs in the upper and middle reaches of the Yellow River, as detailed by Ma et al. (2012) and Chu (2014).

From the timeline in the implementation of the basin-scale water regulation program as detailed earlier and the changing trends of the annual runoff shown in Fig. 2a, it is clear that 2002 is a turning point. Therefore, the runoff and sediment supply to the YRD during 1950-2013 were separated into two periods: 1950-2002 and 2003-2013 and they were represented by the two groups of linear regression relationships:

For 1950-2002:

$$
\begin{aligned}
& Q=-0.92 t+1857 \quad\left(r^{2}=0.53\right) \\
& Q_{S}=-0.021 t+47 \quad\left(r^{2}=0.44\right)
\end{aligned}
$$

\section{For 2003-2013:}

$$
\begin{aligned}
& Q=0.28 t-747 \quad\left(r^{2}=0.10\right) \\
& Q_{s}=-0.015 t+30 \quad\left(r^{2}=0.32\right)
\end{aligned}
$$

where $Q$ is the annual runoff (billion $\mathrm{m}^{3} \mathrm{yr}^{-1}$ ), $Q_{\mathrm{s}}$ is the annual sedi-

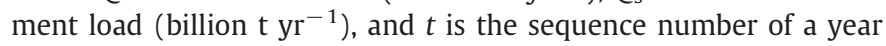
starting from 1950 or 2003.

Eqs. (1) to (4) confirm that the annual runoff was decreasing from 1950 to 2002 but more constant from 2003 until 2013; whereas, sediment supply has been consistently decreasing. This is because sediment comes largely in flooding seasons when the basin-scale water regulation program exerts only limited control to avoid sediment deposition inside reservoirs.

The right side of Fig. 2 presents the temporary variations of runoff and sediment observed at the Lijin station from 1976 to 2013, during which the Yellow River adopts the Qingshuigou course to the sea, the focus of this study. Both annual runoff and sediment showed declining trends from 1976 to 2002, while from 2002 to 2003 the annual runoff increased significantly off one of its lowest levels and since then has remained less changeable with values of around 20 billion $\mathrm{m}^{3} \mathrm{yr}^{-1}$ (Fig. 2a). Because the joint operation of the four large reservoirs under the water-sediment modulated scheme took place from 2002, the channel bed and floodplain of the lower Yellow River have been scoured considerably (Chu, 2014). The supply of this sediment to the YRD until 2005 has made sediment observed at Lijin station show a significant increase from 2002 to 2003, yet declining gradually from 2003 until 2005-2006 because of the gradual weakening of scouring (Fig. 2b). From 2006 until 2013, values of sediment remained less changeable at

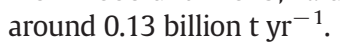

\section{Changes in river mouth channels and delta area}

\subsection{Data extraction}

Remote sensing is an effective means for studying the morphological changes of deltas (e.g. Huang et al., 1994; El-Raey et al., 1999; Yang et al., 1999; Chang et al., 2004; Chu et al., 2006). To evaluate such changes in the estuary of the Yellow River, Landsat MSS, TM and ETM images provided by the USGS covering a period of 40 years are used here (http://glovis.usgs.gov/). Because the Yellow River switched to the Qingshuigou course to the sea since 1976 and this overlaps with the available period of remote sensing, these images provide very suitable evidence of the delta's morphological change.

The tidal regime in the estuary of the Yellow River is characterized by an irregular semi-diurnal form in the Bohai Sea with a maximum range of $0.7-1.8 \mathrm{~m}$, increasing gradually from the north to the south (Qin et al., 1985). In addition, the remote sensing images for the Yellow River delta were taken each time around 10:30 locally (around 2:30 at UTC time) where the tides are relatively low, but the lunar days when the images were taken vary from the beginning to the end of the month. Hence, the remote sensing images accommodate a wide-range variation of tides and the impact of the tides needs to be taken into account in evaluating changes in river mouth channels and shorelines. Since the reflectance of water is nearly equal to zero in reflective infrared bands of remote sensing, the reflectance of the majority of land cover is greater than water. As demonstrated in previous studies (e.g., Chu et al., 2006; Cui and Li, 2011; Kuenzer et al., 2014), remote sensing images normally display a distinct water-land boundary, which can be determined on a GIS platform.

The coastlines extracted from the remote sensing images, however, are the result of the temporary variations of lunar and wind-driven tides, and so it is necessary to minimize the effects of the variations in order to find the coastlines at mean sea level. Although it is not possible to obtain detailed elevation information from remote sensing images, a relatively high interface that does not encounter much disturbance from normal lunar and wind-driven tides can be identified. Studies of Chang et al. (2004) and Liu et al. (2006) on the coastal line changes of the Yellow River delta have demonstrated that such an interface is indeed determinable from remote sensing images. Because normal lunar and wind-driven tides cannot overtop the land above the interface except during very large tides, soil water and salt in the less frequently inundated areas are significantly different from those on lower surfaces experiencing more frequent inundation by tides. In addition, prolonged periods of exposure to the air enable the growth of salt marsh and shrubs. All of these make the land above the interface take a specific reflectance in remotely sensed images and thus areas of commonly exposed land can be determined with an automatic segmentation method with the interface being drawn by hand on a GIS platform. The difference between the high interface and the low water-land boundary illustrates the varying range of normal tides, and so statistically the mean tidal level can be represented with the average of the differences over a sufficiently long time.

Because the river mouth channels in the Yellow River delta have avulsed about once every 10 years over the past century, decadal time-lapsed remote sensing images were selected for this study. Furthermore, the water impoundment of the Xiaolangdi Reservoir from the end of 1999 and the implementation of a water-sediment modulated scheme from 2002 have exerted very significant influences on runoff and sediment delivered to the lower reach and estuary, typically in the experimental period of the scheme from 2002 to 2005 as shown earlier. Hence, changes in the experimental period need to be assessed in a more detailed form, for which 2002, 2003 and 2005 are taken into account. As a result, this study selected nine Landsat remote sensing images taken from 1977 to 2014 which include the years of 1977, 1987, 1996, 2000, 2002, 2003, 2005, 2009 and 2014. Moreover, the watersediment modulated scheme has been implemented in June each year, 
and thus we selected images taken in May to avoid this possible disturbance. All these selected images have a cloud cover of less than $30 \%$ (Fig. 3).

The spatial resolution of the MSS image taken in 1977 is $80 \mathrm{~m}$, while that of the other eight TM images is $30 \mathrm{~m}$. The color composite images with MSS 432 and TM 543 as Red, Green and Blue (RGB), respectively, were acquired using ENVI 4.6 software. Then, ArcGIS 10.0 was used to calculate the land area above the high interface that is not subject to frequent inundations of tidal water and the area between the high interface and the temporary land-water boundary. On the platform, the high interface, the land-water boundary and river mouth channels were drawn manually.

\subsection{Changing patterns of river mouth channels and shorelines}

Figs. 4 and 5 show the changes in the river mouth channels at the mean tidal level delineated from the selected remote sensing images for 1977 to 2014. The river mouth channels on the delta display complex spatial and temporal distributions. They have experienced two significant avulsions since 1976. Before 1996, the river occupied an essentially straight single channel southeast to the sea, increasing its length significantly over that period. In 1996, it avulsed northeastward in the upper part of the old mouth channel, significantly reducing its length to the sea. During 2005-2009, it avulsed northward once again but from a downstream part of the new channel, forming a small delta lobe with two or more channels discharging water and sediment to the sea (Fig. 4). In each avulsion, new mouth channel increases its length rapidly, while the old mouth channel shrinks significantly because of the turnoff of river flow and sediment supply (Fig. 5)

Figs. 6 and 7 show the changes in the shorelines and land-accretion area of the YRD at the mean tidal level delineated from the selected sensing images in the period of 1976 to 2014 . The shorelines are closely related to the development of river mouth channels. In the early stage of a new mouth channel development, the shorelines expand seaward at a fast pace, but when the mouth channel is abandoned, they shrink quickly. As a result, the land of the delta accretes at one place and yet reduces at another (Fig. 6). Nevertheless, the accumulative land-accretion in the YRD shows an increasing trend from 1977 to 2013, while in the period 2000-2009 the land-accretion shows a dramatic loss and then a large gain (Fig. 7). Since 2009, there has been almost no land accretion in
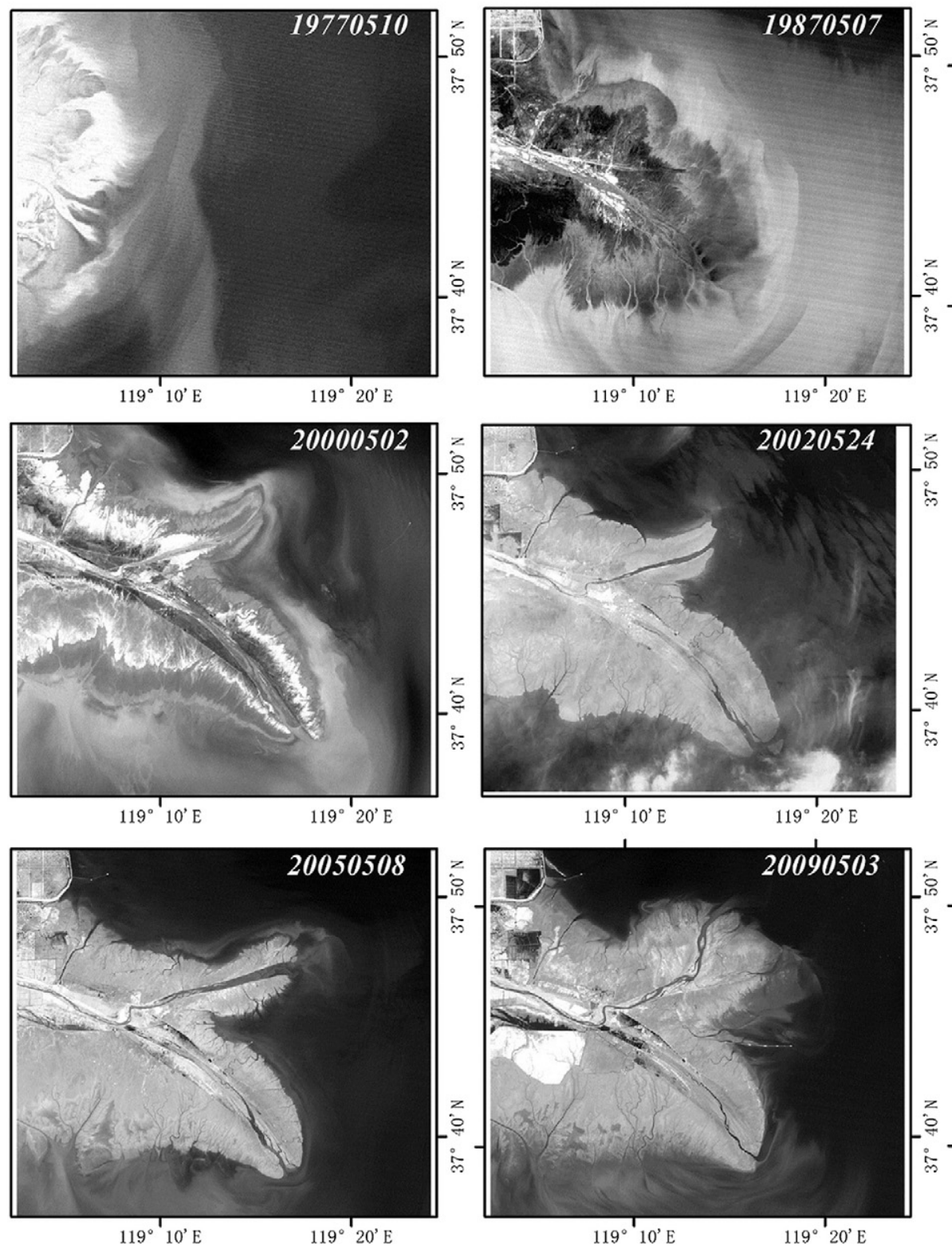
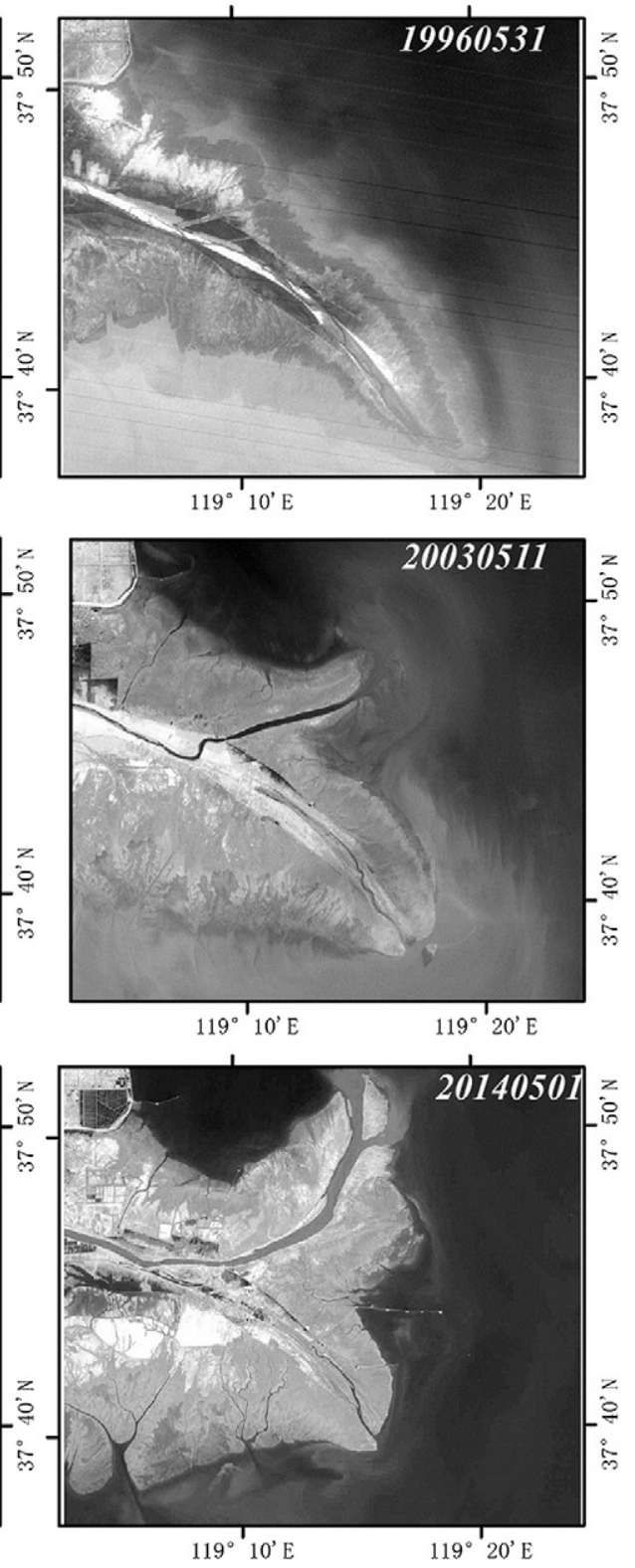

Fig. 3. Remote sensing images of the modern delta of the Yellow River in nine scenes from 1976 to 2013. 


\section{Bohai Sea}

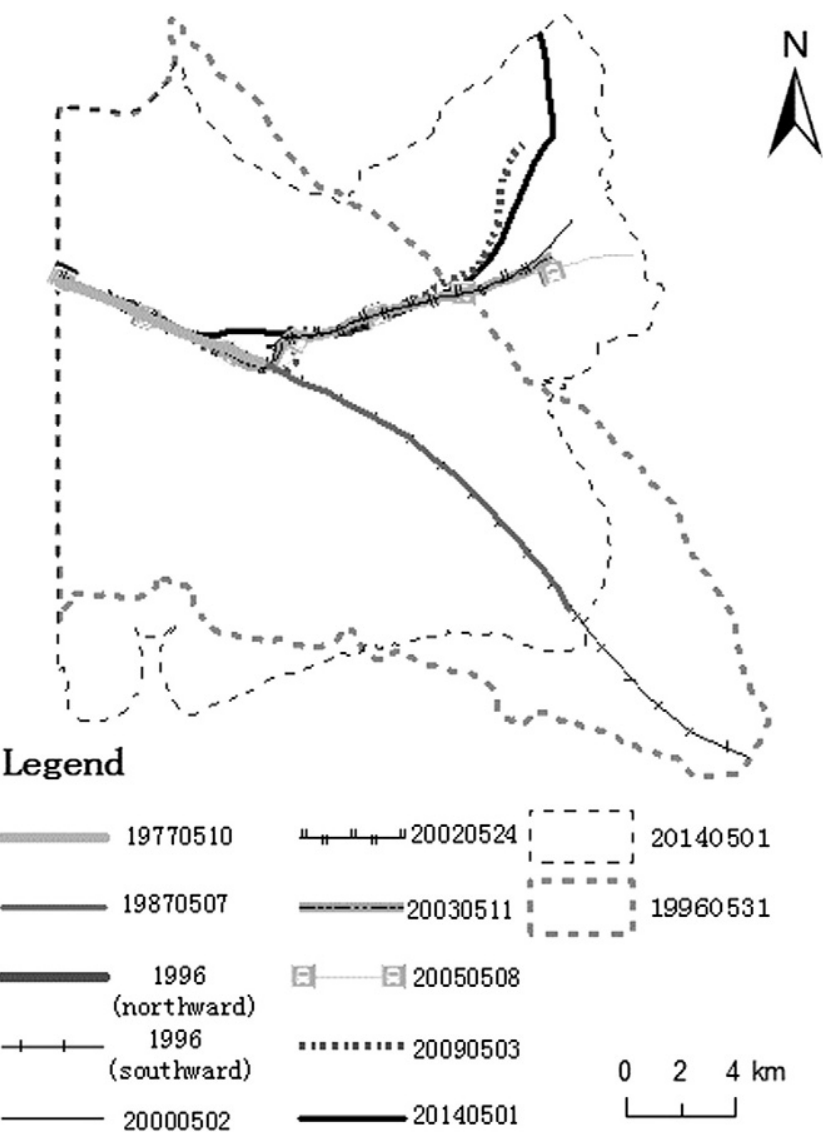

Fig. 4. Changes of river mouth channels in the Yellow River delta during 1976-2013.

the YRD. As described earlier, this is mainly due to the water impoundment of the Xiaolangdi Reservoir and the joint operation of the four large reservoirs.

Over the entire period of 37 years, the land accreted by $191 \mathrm{~km}^{2}$, with an average annual increase rate of $5.16 \mathrm{~km}^{2} \mathrm{yr}^{-1}$. Temporally, however, the centerlines of the two mouth channels and the average growth rates of land-accretion in the delta show firstly a decreasing

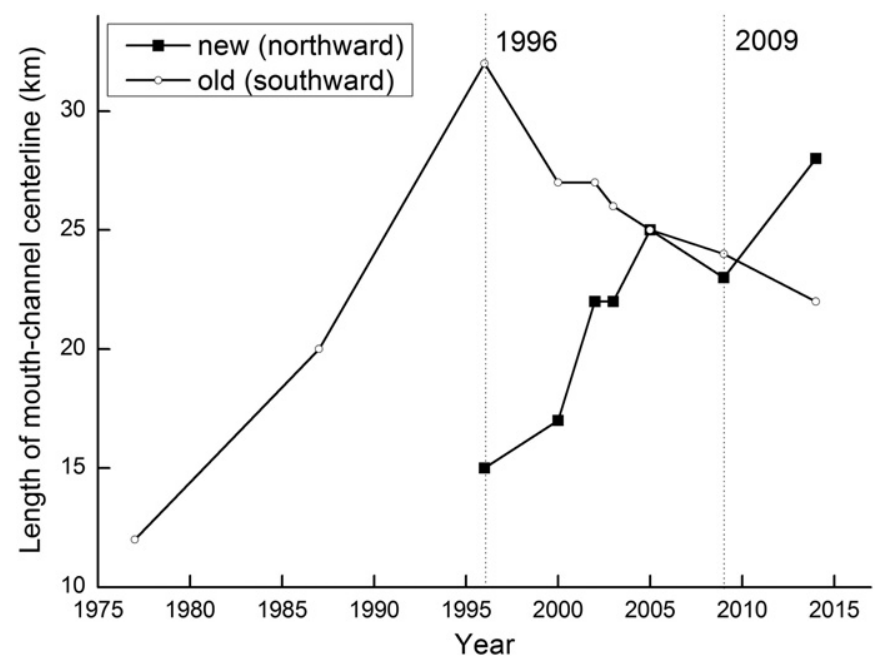

Fig. 5. Changes of the length of the mouth-channel centerline for both old (southward since 1976) and new (northward since 1996) mouth channels in the Yellow River delta during 1976-2013.
Bohai Sea

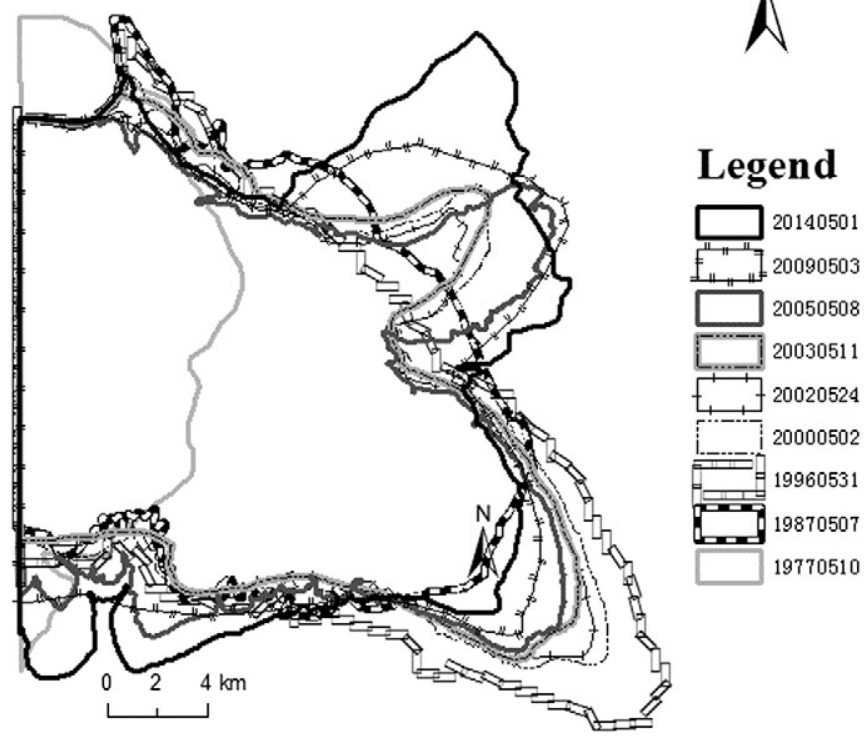

Fig. 6. Changes of the shorelines in the Yellow River delta in the different periods of 1976-2013.

and then an increasing trend before and after 2002 (Fig. 8a). During 1977-1996 (before the first avulsion of the mouth channel) and 1996-2014 (after the first avulsion), the land area of the delta increased by 88 and $103 \mathrm{~km}^{2}$, respectively (Fig. 8a) and the two mouth channels extended by 20 and $12 \mathrm{~km}$, respectively (Fig. 8b). During the period from 1977 until 2014, the highest extension rate in the centerline of the mouth channels occurred from 2000 until 2002, with an extension of $5 \mathrm{~km}$ in the total length at a rate of $2.4 \mathrm{~km} \mathrm{yr}^{-1}$ (Fig. $8 \mathrm{c}, \mathrm{d}$ ).

After the avulsion in 1996, the old mouth channel started to erode back rapidly with a mean rate of $-0.52 \mathrm{~km} \mathrm{yr}^{-1}$ (Fig. 8e). From 2002, the new mouth channel started to grow into the sea from its north bank. However, in the period 2002-2003, both centerlines of the old and new mouth channels shrank with mean rates of $-2.98 \mathrm{~km} \mathrm{yr}^{-1}$ and $-1.0 \mathrm{~km} \mathrm{yr}^{-1}$, respectively (Fig. 8d).

The fastest land accretion and erosion in the estuary occurred between 2000 and 2002 and between 2002 and 2003, with mean rates of 30 and $24 \mathrm{~km}^{2} \mathrm{yr}^{-1}$, respectively (Fig. 8b). These are low compared with the average land accretion rate of nearly $40 \mathrm{~km}^{2} \mathrm{yr}^{-1}$ for the YRD during 1954-1982 reported by Wang et al. (2005); clearly land accretion in the delta slowed down between 1977 and 2014.

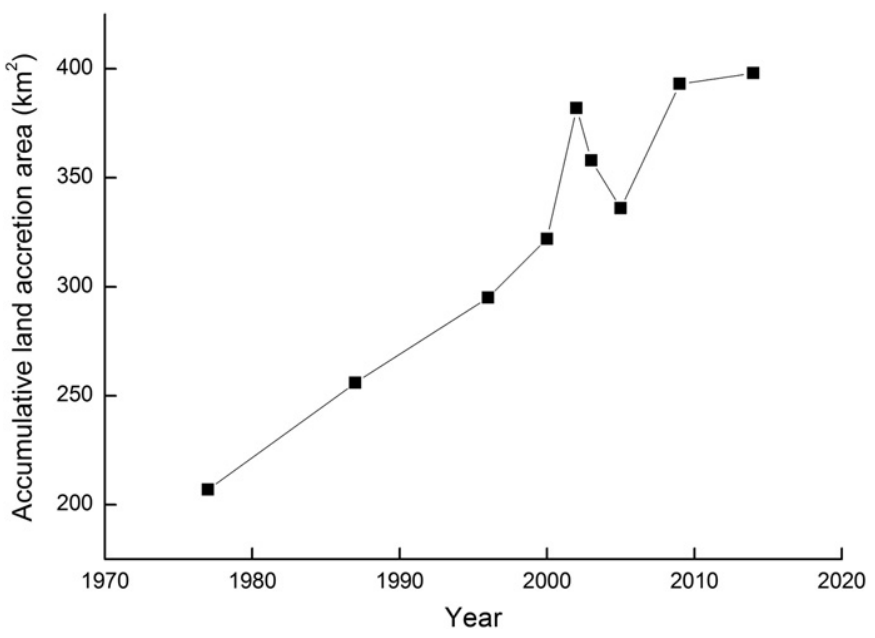

Fig. 7. Changes of the accumulated land area of the Yellow River delta during 1976-2013. 
(a)

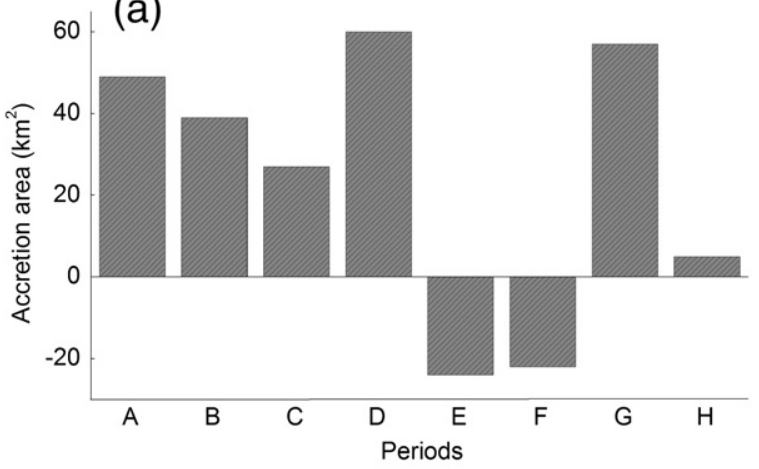

(c)

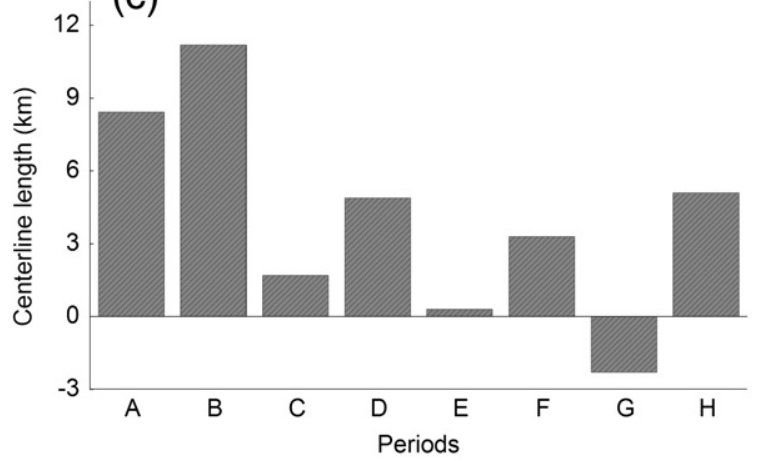

(e)

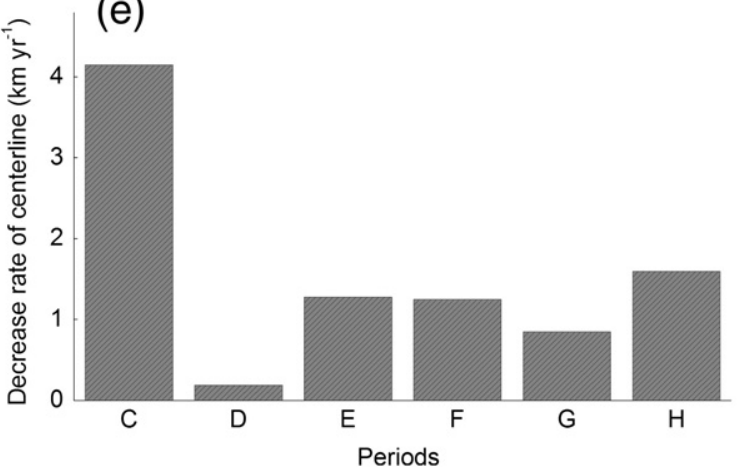

(b)

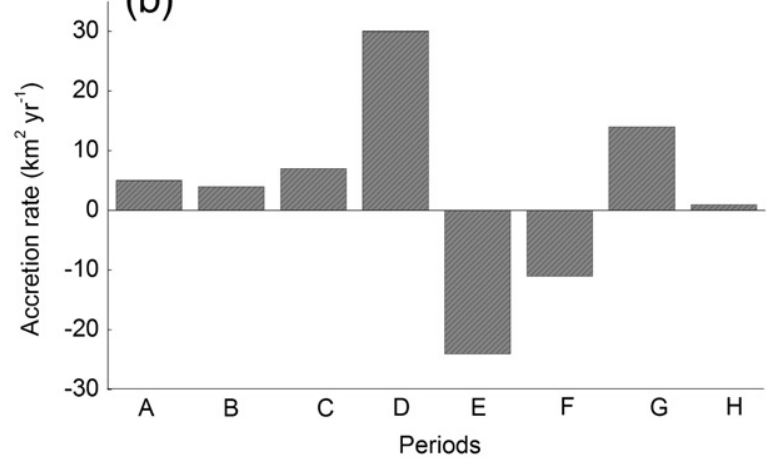

(d)

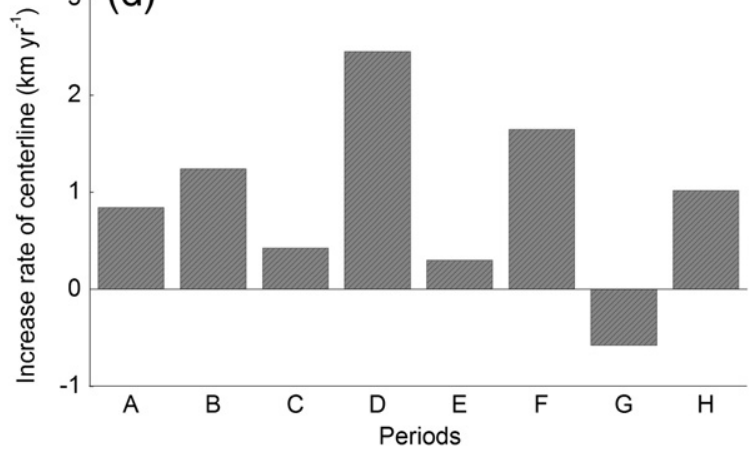

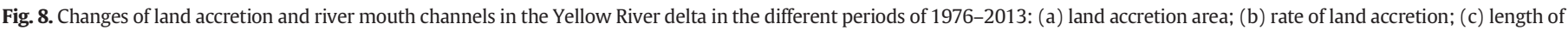
river mouth channel; (d) increasing rate of the mouth channel; and (e) decreasing rate of the mouth channel.

\section{Relationship between land-accretion and water and sediment supply}

Sediment provides the material for land creation in deltas and so it has been regarded as the major factor determining the development of the YRD. Wang et al. (2006) in particular showed that there is a close correlation between sediment input and land-accretion in both the estuary and the delta of the Yellow River in the separate periods of 1953-1973 (Shenxiangou and Diaokouhe courses) and 1976-1997 (Qingshuigou course). While this proposition gained support from Bi et al. (2014) in their analysis of the estuarine change of the YRD in the period 2002-2011, Cui and $\mathrm{Li}$ (2011) identified that besides the close correlation with sediment input, land-accretion of the YRD in the period 1976-2005 also correlates closely with the quantity of water supplied from the river. In addition, these previous studies have focused on the delta's morphologic change only in specific short periods and/or on just parts of the delta, so it is necessary to examine if the correlations exist between land-accretion with sediment input and water supply over the delta for a long period.

There are many datasets available about the land-accretion change in the YRD, but they were obtained at different tidal levels. The datasets from Wang (1985) and Xu (2002) are examined in this study, together with the new dataset, because the former two datasets cover a long period from 1955 to 2013 and illustrate the corresponding land-accretion change over the delta at mean sea or mean tide level. The dataset of Wang (1985) has been officially accredited and was obtained through computing the variation of land-accretion area in the YRD in the period 1955-1980 representing the yearly area change in the zero-meterdepth contours of the sea charts surveyed for navigation in the Yellow River estuary. Xu (2002) obtained his dataset by extracting the waterland boundaries of the YRD from remote sensing images taken in the period 1981-1989 and then corrected the extracted data so that they can represent the coastlines approximately at mean tidal level. As detailed earlier, the dataset obtained in this study is based on the mean tidal level of the YRD.

Fig. 9 presents the integration of the collected three datasets. Because the datasets overlap in the period 1976-1989, the integration provides an opportunity to examine if the land-accretion data obtained in this study deviates significantly from those previously measured.

In Fig. 9 the plots of the land-accretion area in the YRD against either runoff or sediment from the three datasets do not deviate significantly and fall in essentially consistent ranges. This justifies the use of the 

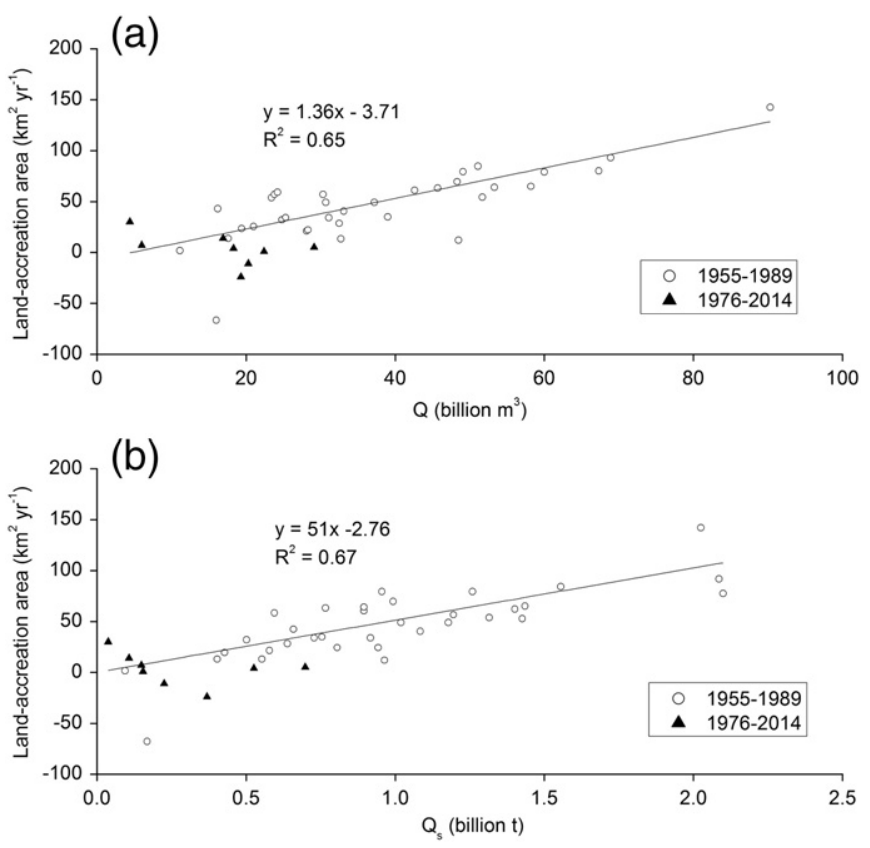

Fig. 9. Relationships of land accretion area in the Yellow River delta with inputs of runoff and sediment separately during 1955-2013.

dataset obtained in this study using remote sensing images. The integrated datasets provide the following linear regression relationships:

$R_{A}=1.36 Q-3.71 \quad\left(r^{2}=0.65\right)$

$R_{A}=51 Q_{S}-2.76 \quad\left(r^{2}=0.67\right)$

where $R_{A}$ is the yearly land-accretion area $\left(\mathrm{km} \mathrm{yr}^{-1}\right)$.

Eqs. (5) and (6) indicate that both runoff and sediment have close relationships with the land-accretion area. To represent the integrated effects of runoff and sediment supply, the following multi-variant linear regression relationship was determined:

$R_{A}=0.63 Q+30.9 Q_{S}-6.07 \quad\left(r^{2}=0.71\right)$.

Fig. 10 plots the calculated land-accretion area using Eq. (7) against the measured land-accretion in the three datasets. Although some

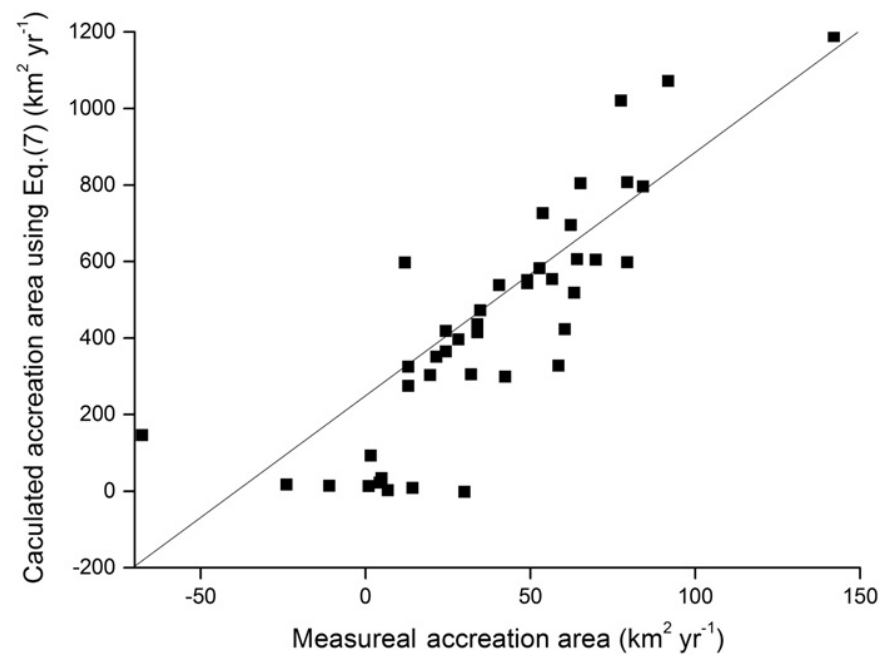

Fig. 10. Land accretion area computed using Eq. (7) against the measured in the Yellow River delta during 1955-2013. scatters exist around the line of perfect agreement, the distribution tends to follow the line, justifying the use of the multi-variant linear model.

\section{Critical water and sediment supply for land accretion}

Because the YRD has been continuously creating new land since its inception, the significant declines in the water and sediment supply to the delta over the last several decades have aroused considerable concerns for those interested in agriculture and socio-economic development and those concerned with wetland conservation for wildlife (Zhu et al., 2003; Wang et al., 2010; Kuenzer et al., 2014). To address these issues, several studies have estimated the minimum amount of sediment input and/or water supply required before net erosion of the YRD occurs. Table 2 presents the results of these previous studies and shows that some determined only the critical sediment condition for the land accretion (e.g. Wang et al., 2006; Bi et al., 2014), whereas others determined both critical water and sediment conditions, yet quite separately (e.g. Cui and Li, 2011). In some cases different critical sediment and water conditions were given for different time periods, even in the same study (e.g. Wang et al., 2006; Cui and Li, 2011). Furthermore, the critical sediment and water conditions given in the previ-

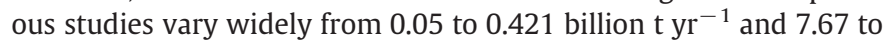
14.0 billion $\mathrm{m}^{3} \mathrm{yr}^{-1}$, respectively (Table 2 ). These make the results in Table 2 difficult to use for the evaluation of the effects of the basinscale water regulation program on the progradation of the YRD.

As demonstrated earlier in this study, Eq. (7) covers a substantial period of time, including those periods addressed in the previous studies (Table 2). Importantly, Eq. (7) quantifies the effects of both water and sediment supply on the land accretion of the YRD in an integrated way, a methodological advance over the previous studies. Eq. (7) can be used to determine the critical water and sediment condition for land accretion in the YRD. By letting $R_{A} \geq 0$, Eq. (7) yields:

$Q \geq 49.05\left(0.2-Q_{s}\right)$

or

$Q_{s} \geq 0.02(9.63-Q)$

Eqs. (8) and (9) show that $Q_{s}$ and $Q$ have respective critical values of

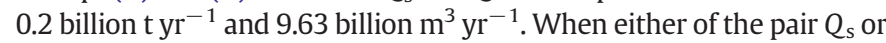
$Q$ takes a value larger than its respective critical value, the land accretion occurs irrespective of the value of another parameter. On the contrary, when either of the pair $Q_{s}$ or $Q$ takes a value less than its respective critical value, whether the land accretion occurs or not depends on the value of another parameter. When $Q_{s}$ takes values of $0.05,0.1$ and

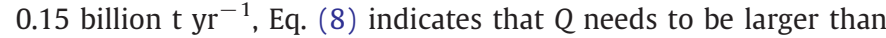
$7.36,4.905$, and 2.45 billion $\mathrm{m}^{3} \mathrm{yr}^{-1}$, respectively. Clearly, with more sediment contributing to the accretion of new land in the YRD, less water is required in order to achieve the critical condition. Consistently, when $Q$ takes values of 9, 6, 3 and 1 billion $\mathrm{m}^{3} \mathrm{yr}^{-1}$, Eq. (9) indicates

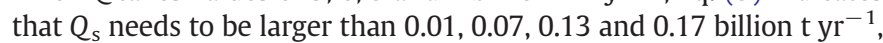

Table 2

Factors affecting land accretion in YRD adopted in previous studies and the obtained corresponding critical amount of runoff and sediment input.

\begin{tabular}{cllll}
\hline Author(s) & Period(s) & Factor(s) & $\begin{array}{l}\text { Critical sediment } \mathrm{Q}_{\mathrm{s}} \\
\text { (billion } \mathrm{yr}^{-1} \text { ) }\end{array}$ & $\begin{array}{l}\text { Critical runoff } \mathrm{Q} \\
\text { (billion } \mathrm{m}^{3} \mathrm{yr}^{-1} \text { ) }\end{array}$ \\
\hline Xu (2002) & $1955-1989$ & $\mathrm{Q}_{\mathrm{s}}, \mathrm{Q}$ & 0.278 & 7.67 \\
Wang et al. & $1953-1973$ & $\mathrm{Q}_{\mathrm{s}}$ & 0.421 & \\
$\quad$ (2006) & $1976-1997$ & $\mathrm{Q}_{\mathrm{s}}$ & 0.151 & 14.0 \\
Cui and Li & $1975-2005$ & $\mathrm{Q}_{\mathrm{s}}, \mathrm{Q}$ & 0.331 & 8.5 \\
$\quad$ (2011) & $1996-2005$ & $\mathrm{Q}_{s}, \mathrm{Q}$ & 0.163 & \\
Bi et al. (2014) & $2002-2011$ & $\mathrm{Q}_{\mathrm{s}}$ & 0.05 &
\end{tabular}


respectively. Hence, with less water contributing to the accretion of new land, more sediment is required to achieve the critical condition.

As shown in Table 1 and Fig. 3b, the sediment input to the YRD vary around $0.13 \mathrm{t} \mathrm{yr}^{-1}$ in the latest period, 2006-2013. This is below 0.2 billion $\mathrm{t} \mathrm{yr}^{-1}$, the minimum sediment requirement presented in Eq. (8). Therefore, care needs to be taken in the future implementation of the basin-scale water regulation program in order to ensure that no land in the YRD will be lost to ocean.

Although this study highlights the importance of the critical water and sediment condition and the methodological advance in determining the critical condition, the present analysis is still preliminary and general. It has not considered the adjusting process of channel geometry and gradient, as well as the reworking process of sediments deposited around the mouth channels. More detailed studies of the dynamic interactions among river flow, sediment movement, estuarine and coastal morphology, and tidal and oceanic flow at multiple tempo-spatial scales should be conducted in the future.

\section{Conclusions}

The construction of numerous small to large reservoirs, the implementation of water and soil conservation measures and a water regulation program across the Yellow River basin have produced widely recognized changes in the water and sediment yield of river since the mid 1960s. To evaluate how these changes have affected progradation of the YRD, this study presented a detailed analysis of the changing patterns of water and sediment delivered to the delta from 1950 to 2013 and examined changes in the river mouth channels and shorelines of the delta from 1976 to 2013 using remote sensing. An integrated relationship between land accretion on the YRD and the annual runoff and sediment yields at the Lijin station was analyzed. The effects of the implementation of the basin-scale water regulation program were evaluated.

During the period of markedly reduced water and sediment delivery to the YRD from 1976 until 2013, a significant change occurred in 2002-2005, after which the supply of water and sediment tended to be constantly low. This was due to the implementation of the water regulation program in the drainage basin and contrasts to the interpretations of most previous studies that indicated more continuous decline of water and sediment supply.

In response to the changes in water and sediment supply, the growth rates of river mouth channels, shorelines and land area change from an increasing trend to a declining one. The period from 2000 to 2005 was transitional, during which the delta's morphology shows very complex changes.

Integrating all available data for the period 1955-2013, we have developed of a relationship showing the integrated effects of sediment and water supply on land accretion in the YRD. The relationship was used to define the critical values of sediment and water supply to the YRD. For decision-making on the implementation of the basin-scale water regulation program, however, further detailed theoretical studies are needed.

\section{Acknowledgments}

This work was financially supported by the National Natural Science Foundation of China (Grant Nos. 41371036, 40788001) and the International Science \& Technology Cooperation Program of China (2012DFG22050). The authors would like to thank the United States Geological Survey (USGS) for providing free Landsat satellite data on the Yellow River delta, and the Yellow River Water Conservancy Commission of China for permission to access the observed hydrological data. Takashi Oguchi, Jeff Nittrouer and an anonymous reviewer are all thanked for their valuable comments which significantly enhance the quality of this paper.

\section{References}

Allison, M.A., Nittrouer, C.A., Faria, J.L.E.C., 1995. Rates and mechanisms of shoreface progradation and retreat downdrift of the Amazon River mouth. Mar. Geol. 125 (3), 373-392.

Bi, N., Wang, H.J., Yang, Z.S., 2014. Recent changes in the erosion-accretion patterns of the active Huanghe (Yellow River) delta lobe caused by human activities. Cont. Shelf Res. 90, 70-78.

Blum, M.D., Roberts, H.H., 2009. Drowning of the Mississippi Delta due to insufficient sediment supply and global sea-level rise. Nat. Geosci. 2 (7), 488-491.

Bridge, J., 2003. Rivers and Floodplains: Forms, Processes, and Sedimentary Record. Blackwell Science, UK

Cai, X., Rosegrant, M.W., 2004. Optional water development strategies for the Yellow River basin: balancing agricultural and ecological water demands. Water Resour. Res. 40, W08S04. http://dx.doi.org/10.1029/2003WR002488.

Chang, J., Liu, G.H., Liu, Q.S., 2004. Dynamic monitoring of coastline in the Yellow River Delta by remote sensing. J. Geogr. Inf. Sci. 1, 94-98 (in Chinese).

Chen, J.G., Zhou, W.H., Chen, Q., 2012. Channel re-establishment of the Lower Yellow River in ten years operation of Xiaolangdi Reservoir. J. Hydrodyn. 24 (6), 127-135.

Chen, Y., Zhu, Z., Zhang, Z., 2002. The Yellow River water dispatching and management system. Yellow River 24 (5) (in Chinese).

Chinese Academy of Sciences, 1980. Chinese Natural Geography and Geomorphology. Compilation Committee of Chinese Natural Geography, Chinese Academy of Sciences. Scientific Publishing House, Beijing

Chu, Z.X., 2014. The dramatic changes and anthropogenic causes of erosion and deposition in the lower Yellow (Huanghe) River since 1952. Geomorphology 216, 171-179.

Chu, Z.X., Sun, X.G., Zhai, S.K., Xu, K.H., 2006. Changing pattern of accretion/erosion of the modern Yellow River (Huanghe) subaerial delta, China: based on remote sensing images. Mar. Geol. 227, 13-30.

Cui, B.L., Li, X.Y., 2011. Coastline change of the Yellow River estuary and its response to the sediment and runoff (1976-2005). Geomorphology 127 (1), 32-40.

El-Raey, M., El-Din, S.S., Khafagy, A.A., Abo Zed, A.I., 1999. Remote sensing of beach erosion/accretion patterns along Damietta-Port Said shoreline, Egypt. Int. J. Remote Sens. 20 (6), 1087-1106

Fan, H., Huang, H., Zeng, T.Q., 2006a. Impacts of anthropogenic activity on the recent evolution of the Huanghe (Yellow) River Delta. J. Coast. Res. 22 (4), 919-929.

Fan, H., Huang, H., Zeng, T.Q., Wang, K., 2006b. River mouth bar formation, riverbed aggradation and channel migration in the modern Huanghe (Yellow) River Delta, China. Geomorphology 74 (1), 124-136.

Ganti, V., Chu, Z., Lamb, M.P., Nittrouer, J.A., Parker, G., 2014. Testing morphodynamic controls on the location and frequency of river avulsions on fans versus deltas: Huanghe (Yellow River), China. Geophys. Res. Lett. 41, 7882-7890. http://dx.doi.org/10.1002/ 2014 GL061918.

Giodano, M., Zhu, Z., Cai, X., Hong, S., Zhang, X., Xue, Y., 2004. Water management in the Yellow River Basin: background, current critical issues and future research needs. Comprehensive Assessment Research Report 3. Comprehensive Assessment Secretariat, Colombo, Sri Lanka.

Hillel, D., 1991. Lash of the dragon. Nat. Hist. 29-37 (August)

Hu, C.H., Cao, W.H., 2003. Variation, regulation and control of flow and sediment in the Yellow River estuary: part 1: mechanism of flow-sediment transport and evolution. J. Sediment. Res. 5, 1-8 (in Chinese).

Huang, H.J., Li, C.Z., Guo, J.C., 1994. Application of Landsat images the studies of the shoreline changes of the Huanghe River delta. Mar. Geol. Quat. Geol. 14 (2), 29-37.

Kuenzer, C. Ottinger, M., Liu, G., Sun, B. Baumhauer, R., Dech, S., 2014. Earth observationbased coastal zone monitoring of the Yellow River Delta: dynamics in China's second largest oil producing region over four decades. Appl. Geogr. 55, 92-107.

Lamb, M.P., Nittrouer, J.A., Shaw, J., Mohrig, D., 2012. Backwater and river-plume controls on scour upstream of river mouths: implications for fluvio-deltaic morphodynamics. J. Geophys. Res. 117. http://dx.doi.org/10.1029/2011JF002079.

Li, G., Wei, H., Yue, S., Cheng, Y., Han, Y., 1998. Sedimentation in the Yellow River delta: part II. Suspended sediment dispersal and deposition on the subaqueous delta. Mar. Geol. 149, 103-121.

Li, S., Finlayson, B., 1993. Flood management on the lower Yellow River: hydrological and geomorphological perspectives. Sediment. Geol. 85, 285-296.

Lian, Y., Wang, X., Huang, C., Liu, G., Wang, R., Zhang, S., Liu, Y., Pedroli, B., van Eupen, M., 2008. Environmental flows evaluation based on eco-hydrology in the Yellow River Delta wetlands. Acta Geograph. Sin. 63 (5), 451-461.

Liu, F., Yang, Q., Chen, S., Luo, Z., Yuan, F., Wang, R., 2014. Temporal and spatial variability of sediment flux into the sea from the three largest rivers in China. J. Asian Earth Sci. $87,102-115$

Liu, G.H., Liu, Q.S., Ye, O.H., Chang, J., 2006. Monitoring ecosystem change and land resources utilization in the Yellow River Delta. Resour. Sci. 5, 171-175 (in Chinese).

Ma, Y., Huang, H.Q., Nanson, G.C., Li, Y., Yao, W., 2012. Channel adjustments in response to the operation of large dams: the upper reach of the lower Yellow River. Geomorphology $147,35-48$.

McManus, J., 2002. Deltaic responses to changes in river regimes. Mar. Chem. 3-4 (79), 155-170.

Milliman, J.D., Meade, R.H., 1983. World-wide delivery of river sediment to the oceans. J. Geol. 91, 1-21.

Nanson, R.A., Vakarelov, B.K., Ainsworth, R.B., Williams, F.M., Price, D.M., 2013. Evolution of a Holocene, mixed-process, forced regressive shoreline: the Mitchell River delta, Queensland, Australia. Mar. Geol. 339, 22-43.

Ottinger, M., Kuenzer, C., Liu, G., Wang, S., Dech, S., 2013. Monitoring land cover dynamics in the Yellow River Delta from 1995 to 2010 based on Landsat 5 TM. Appl. Geogr. 44, 53-68. 
Pang, J.Z., Si, S.H., 1980. Fluvial process of the Huanghe River estuary. Chin. J. Oceanol. Limnol. 11 (4), 295-305 (in Chinese).

Peng, J., Chen, S., Dong, P., 2010. Temporal variation of sediment load in the Yellow River basin, China, and its impacts on the lower reaches and the river delta. Catena 83 (2), 135-147.

Qin, Y.S., Zhao, Y.Y., Zhao, S.L., 1985. Geology of Bohai Sea. Science Press, Beijing, pp. 61-66 (in Chinese).

Ren, M., Shi, Y., 1986. Sediment discharge of the Yellow River (China) and its effect on the sedimentation of the Bohai and the Yellow Sea. Cont. Shelf Res. 6, 785-795.

Ringler, C., Cai, X., Wang, J., Ahmed, A., Xue, Y., Xu, Z., Yang, E., Zhao, J., Zhu, T., Cheng, L., Fu, Y., Fu, X., Gu, X., You, L., 2010. Yellow River basin: living with water scarcity. Water Int. 35 (5), 681-701.

Roberts, H.H., 1997. Dynamic changes of the Holocene Mississippi River delta plain: the delta cycle. J. Coast. Res. 13, 605-627.

Saito, Y., Chaimanee, N., Jarupongsakul, T., Syvitski, J.P., 2007. Shrinking megadeltas in Asia: sea-level rise and sediment reduction impacts from case study of the Chao Phraya Delta. Inprint Newsletter of the IGBP/IHDP Land Ocean Interaction in the Coastal Zone 2, pp. 3-9.

Saito, Y., Wei, H., Zhou, Y., Nishimura, A., Sato, Y., Yokota, S., 2000. Delta progradation and chenier formation in the Huanghe (Yellow River) delta, China. J. Asian Earth Sci. 18 (4), 489-497.

Saito, Y., Yang, Z., Hori, K., 2001. The Huanghe (Yellow River) and Changjiang (Yangtze River) deltas: a review on their characteristics, evolution and sediment discharge during the Holocene. Geomorphology 41 (2), 219-231.

Shi, C., Zhang, D., 2003. Processes and mechanisms of dynamic channel adjustment to delta progradation: the case of the distributaries of the Yellow River, China. Earth Surf. Process. Landf. 28, 609-624.

Van Gelder, A., Van den Berg, J.H., Cheng, G., Xue, C., 1994. Overbank and channel fill deposits of the modern Yellow River delta. Sediment. Geol. 90, 293-305.

Wang, H.J., Bi, N., Saito, Y., Wang, Y., Sun, X., Zhang, J., Yang, Z., 2010. Recent changes in sediment delivery by the Huanghe (Yellow River) to the sea: causes and environmental implications in its estuary. J. Hydrol. 391 (3-4), 302-313.

Wang, H.J., Yang, Z.S., Bi, N., Li, H., 2005. Rapid shifts of the river plume pathway off the Huanghe (Yellow) River mouth in response to Water-Sediment Regulation Scheme in 2005. Chin. Sci. Bull. 50, 2878-2884.

Wang, H.J., Yang, Z.S., Saito, Y., Liu, J.P., Sun, X.X., Wang, Y., 2007. Stepwise decreases of the Huanghe (Yellow River) sediment load (1950-2005): impacts of climate change and human activities. Glob. Planet. Chang. 57 (3), 331-354.

Wang, K.C., 1985. A method for estimating the developmental tendency of the Yellow River Delta and the corresponding influences. Research Report of the Institute of the Yellow River Scientific Research, Zhengzhou (in Chinese).

Wang, K.C., 2010. Evolution of the Yellow River Estuary and Management. The Yellow River Water Conservancy Press, Zhengzhou (in Chinese).

Wang, K.R., 2005. Impact and evaluation of water and sediment regulation in the Yellow River on the estuary and its delta. J. Sediment. Res. 6, 29-33 (in Chinese).
Wang, Q., Cao, L., Yang, Z., 1992. Sediment-dynamic characteristics of the Huanghe (Yellow) River subaqueous delta. Sci. China B 35, 631-640.

Wang, S.J., Hassan, M.A., Xie, X.P., 2006. Relationship between suspended sediment load channel geometry and land area increment in the Yellow River Delta. Catena 65 (3), 302-314.

Wang, Z.Y., Liang, Z.Y., 2000. Dynamic characteristics of the Yellow River mouth. Earth Surf. Process. Landf. 25 (7), 765-782.

Wang, Z.Y., Yu, G.A., Huang, H.Q., Wang, R.Y., 2012. Gender of large river deltas and parasitizing rivers. Int. J. Sediment Res. 27 (1), 18-36.

Wright, L.D., Coleman, J.N., 1973. Variation in morphology of major deltas as a function of ocean wave and river discharge regimes. Am. Assoc. Pet. Geol. Bull. 57, 177-205.

Wright, L.D., Wiseman, W.J., Yang, Z.S., Bornhold, B.D., Keller, G.H., Prior, D.B., Suhayda, J.N., 1990. Processes of marine dispersal and deposition of suspended silts off the modern mouth of the Huanghe River (Yellow River). Cont. Shelf Res. 10, 1-40.

Xu, J.X., 2002. A study of thresholds of runoff and sediment for the land accretion of the Yellow River Delta. Geogr. Res. 21 (2), 163-170 (in Chinese).

Yang, D., Li, C., Hu, H., Lei, Z., Yang, S., Kusuda, T., Koike, T., Musiake, K., 2004. Analysis of water resources variability in the Yellow River of China during the last half century using historical data. Water Resour. Res. 40, W06502. http://dx.doi.org/10.1029/ 2003WR002763.

Yang, X., Damen, M.C., Van Zuidam, R.A., 1999. Satellite remote sensing and GIS for the analysis of channel migration changes in the active Yellow River Delta, China. Int J. Appl. Earth Obs. Geoinf. 1 (2), 146-157.

Yu, Y.G., Shi, X.F., Wang, H.J., Yue, C.K., Chen, S.L., Liu, Y.G., Hu, L.M., Qiao, S.Q., 2013a. Effects of dams on water and sediment delivery to the sea by the Huanghe (Yellow River): the special role of Water-Sediment Modulation. Anthropocene 3, 72-82.

Yu, Y.G., Wang, H.J., Shi, X.F., Ran, X.B., Cui, T.W., Qiao, S.Q., Liu, Y.G., 2013b. New discharge regime of the Huanghe (Yellow River): causes and implications. Cont. Shelf Res. 69, 62-72.

Zeng, Q., 1997. Evolution of the Yellow River Estuary and Its Countermeasures. Yellow River Water Conservancy Press, Zhengzhou (in Chinese).

Zhang, Z.H., Hu, C.H., 2007a. Variation of flow and sediment and atrophy response of tail channels in the Yellow River estuary. J. Sediment. Res. 5, 13-21 (in Chinese)

Zhang, Z.H., Hu, C.H., 2007b. Variation of the processes of flow and sediment and its effect on epeirogenesis of seacoast in the Yellow River estuary. Adv. Water Sci. 18 (3) 336-341 (in Chinese).

Zhao, Y., Zhou, W., Fei, X., 1997. Basic Evolvement Rule of the Lower Yellow River Channel. Huanghe Water Conservancy Press, Zhengzhou, pp. 1-197 (in Chinese).

Zhou, L.Y., Liu, J., Saito, Y., Zhang, Z.X., Chu, H.X., Hu, G., 2014. Coastal erosion as a major sediment supplier to continental shelves: example from the abandoned Old Huanghe (Yellow River) delta. Cont. Shelf Res. 82, 43-59.

Zhu, Z., Cai, X., Giordano, M., Molden, D., Hong, S., Zhang, H., Lian, Y., Li, H., Zhang, X. Zhang, X., Xue, Y., 2003. Yellow river comprehensive assessment: basic features and issues. Working Paper 57. International Water Management Institute, Colombo, Sri Lanka. 